\title{
Fouling analysis of polysulfone ultrafiltration membranes used for drinking water treatment
}

\author{
B. Q. Zhao, C. P. Huang, S. Y. Chen, D. S. Wang, T. Li and J. H. Qu
}

\begin{abstract}
Natural organic matter (NOM) plays a significant role in the fouling of ultrafiltration membranes in drinking water treatment processes. For a better understanding of the interaction between fractional components of NOM and polysulfone (PS) ultrafiltration membranes used for drinking water treatment, fouling and especially the physically irreversible fouling of natural organic matter were investigated. Resin fractionation, fluorescence excitation-emission matrix (EEM) spectroscopy, fourier transform infrared spectroscopy (FTIR), contact angle and a scanning electron microscope (SEM) were employed to identify the potential foulants. The results showed that humic acid and fulvic acid of small size were likely to permeate the membrane, while the hydrophobic fraction of humic and fulvic acid and aromatic proteins tended to be rejected and retained. Organic compounds such as proteins, humic substances, and polysaccharide-like materials, were all detected in the fouling layer. The physically irreversible fouling of the PS membrane seemed to be mainly attributed to the hydrophobic fraction of humic substances.
\end{abstract}

B. Q. Zhao

D. S. Wang (corresponding author)

T. Li

J. H. QU

Research Center for Eco-Environmental Sciences, Chinese Academy of Sciences, Beijing 100085,

China

E-mail: wgds@rcees.ac.cn

C. P. Huang

S. Y. Chen

Institute of Environmental Engineering

National Chiao Tung University,

Hsinchu 300,

Taiwan

Key words | fouling, NOM, physically irreversible fouling, ultrafiltration

\section{INTRODUCTION}

Membrane technology has rapidly become an efficient alternative to conventional drinking water treatment. The primary limitation encountered in the application of membrane technology is membrane fouling, which results in increases in hydraulic resistances, operational and maintenance costs, and deterioration of productivity and product quality (Aoustin et al. 200I; Yamamura et al. 2007). Much effort has been made to investigate the fouling mechanisms and foulant composition (Zularisam et al. 2007a). Several physical and chemical membrane cleaning methods such as hydraulic backwashing and $\mathrm{NaOH}$ or $\mathrm{HCl}$ solution cleaning have been developed and used routinely in many membrane plants to minimize membrane fouling. Usually, fouling that can be removed by physical cleaning is defined as physically reversible fouling, otherwise it is described as physically irreversible fouling (Yamamura et al. 2007).

Natural organic matter (NOM) consisting of a variety of nonbiodegradable organic compounds including humic substances has been widely reported as the major foulant doi: 10.2166/ws.2011.094 during surface water filtration (Yuan \& Zydney I999; Li \& Elimelech 2004). However, presently there is still little agreement on the relative role of each NOM fraction in membrane fouling, especially on physically irreversible fouling. Previous researchers have suggested that the humic substances fraction of NOM is the major foulant which controls the rate and extent of fouling. Nilson \& DiGiano (I996) investigated the influence of hydrophobic and hydrophilic NOM on nanofiltration; their work showed that the hydrophobic NOM fraction was responsible for nearly the entire flux decline. Aoustin et al. (200I) reported that the larger and more UV-absorbing fraction of humic acid was responsible for the irreversible pore adsorption and plugging. The fulvic acid and the hydrophilic fraction showed a smaller and mostly reversible flux decline.

More recently, as resin fractionation of NOM has been introduced into the investigation of potential fouling, hydrophilic NOM has been reported by several researchers to be a major foulant. Cho et al. (2000) reported that higher 
molecular weight (MW) of the hydrophilic fraction was responsible for flux decline. Polypropylene MF filtration tests showed that small, neutral, hydrophilic compounds were the major NOM foulants for MF membranes. The NOM fractions comprised of humic and fulvic acid made only a minor contribution to membrane fouling (Carroll et al. 2000). Fan et al. (200I) identified the order of potential foulants as being hydrophilic neutral $>$ hydrophobic acids $>$ transphilic acids $>$ hydrophilic charged. They further concluded that the low aromatic hydrophilic neutral compounds were the main determinant of the rate and extent of flux decline. Kennedy et al. (2005) suggested a similar order of fouling potential: hydrophilic > hydrophobic $>$ transphilic. They found that a UF membrane showed almost no rejection for humic acids $(20,000-1,000 \mathrm{Da})$. They also demonstrated that the reversibility of fouling caused by the hydrophilic fraction was very poor. However, Zularisam et al. (2007b) found the hydrophilic fraction of NOM exhibited a better flux recovery than the hydrophobic fraction despite its higher adsorption resistance and greater flux decline. Up to now, there is little agreement on which fraction of NOM is responsible for membrane fouling, especially for physically irreversible fouling.

In this study, fouling and physically irreversible fouling with natural organic matter source waters were investigated for a better understanding of the interactions between fractional components of NOM and a polysulfone (PS) UF membrane. Resin fractionation, fluorescence excitationemission matrix (EEM) spectroscopy, Fourier transform infrared spectroscopy (FTIR), contact angle techniques and a scanning electron microscope (SEM) were employed to explore the nature of foulants and their reversibility, as well as looking at causes.

\section{$\overline{\text { METHODS }}$}

Experiments were carried out at Baoshan water treatment plant (Hsinchu, Taiwan). Influent at the plant (raw water from Baoshan Reservoir) was on-line pretreated with $5 \mu \mathrm{m}$ and $1 \mu \mathrm{m}$ cartridge filters, and then delivered to a crossflow membrane test unit (Sepa ${ }^{\circledR}$ CFII, GE Osmonics) as feed water at a flow rate of $0.8 \mathrm{~L} / \mathrm{min}$ and at a constant trans-membrane pressure (TMP) of 2 bar. The feed, concentrate and permeate were sampled, collected and analyzed every day during the whole operation period (200 hours).

The DOM fractions in the above water samples were further characterized by resin fractionation about which a detailed procedure has been reported by Wei et al. (2008). XAD-8 and XAD-4 resins (Amberlite, Sigma-Aldrich Co., USA) were used to fractionate DOM as follows: (1) the pre-filtered sample (by $0.45 \mu \mathrm{m}$ membrane) was first passed through XAD-8 resin without any $\mathrm{pH}$ adjustment to isolate hydrophobic bases (HoB) and hydrophobic neutral (HoN). (2) HoB was obtained by back-washing the XAD-8 resin immediately with 10 bed-volumes of $0.1 \mathrm{~mol} / \mathrm{L}$ $\mathrm{H}_{3} \mathrm{PO}_{4}$ at 15 bed-volumes/h. The hydrophobic neutral ( $\mathrm{HoN}$ ) could not be desorbed by $\mathrm{H}_{3} \mathrm{PO}_{4}$ and retained in the resin. $\mathrm{H}_{3} \mathrm{PO}_{4}$ was selected because of its minimal impact on the dissolved organic carbon (DOC) measurement compared to $\mathrm{HCl}$ or $\mathrm{HNO}_{3}$. (3) The first effluent of the XAD-8 column was adjusted to $\mathrm{pH} 2$ by $85 \% \mathrm{H}_{3} \mathrm{PO}_{4}$ and then added into this XAD-8 resin column again. The hydrophobic acid (HoA) was adsorbed. (4) The second effluent from the XAD-8 column was passed through XAD-4 resin. The fraction adsorbed by this resin could be described as weakly hydrophobic acid (WHoA), which is also commonly defined as transphilic acid (THPA). (5) Organics contained in the XAD-4 effluent (not retained by either the XAD- 8 or the XAD-4 resins) were named hydrophilic matter (HiM). The resins were cleaned and conditioned as described by Leenheer (I98I) before use.

A flat sheet of PS membrane (GE Osmonics) with a MWCO of $30 \mathrm{kDa}$ was used. It was soaked in methanol for $2 \mathrm{~h}$ before use. When the operation ended, the fouled membrane was taken out. A part of the membrane was cut and manually wiped with a sponge and thoroughly rinsed with DI water to remove the accumulated physically reversible cake layer. The original fouled membrane and the sponged wiped membrane were then analyzed using ATR-FTIR (Bomem, DA8.3, Canada), contact angle analysis techniques (MagicDroplet Model 100, USA) and an SEM (Hitachi S-4700, type II, Japan) after drying.

Analysis of DOC was performed by a TOC analyzer (TOC-5000A, Shimadzu, Japan). Measurements of 
absorbance at the wavelength of $254 \mathrm{~nm}\left(\mathrm{UV}_{254}\right)$ were carried out using a UV-Vis spectrophotometer (U3010, Hitachi, Japan) with a $1 \mathrm{~cm}$ quartz cell. Each EEM was generated by scanning excitation wavelengths from 200 to $400 \mathrm{~nm}$ with $10 \mathrm{~nm}$ steps, and detecting the emitted fluorescence between 250 and $550 \mathrm{~nm}$ with $1 \mathrm{~nm}$ steps. DI water was measured as a quality control for daily analysis. The $\mathrm{pH}$ value of water samples were controlled at 7 .

\section{RESULTS AND DISCUSSION}

\section{Membrane filtration}

Figure 1 shows the flux behaviour of the PS membrane filtration. The flux declined fast during the first two days of the filtration and decreased to about $40 \%$ of the initial membrane flux. Severe fouling is observed with a flux decline of $70 \%$ at the end of the operation.

\section{Characteristics of water streams}

The average quality of the feed, permeate and concentrate was calculated based on daily analyses during the whole operation period and the results are shown in Table 1 . It can be seen that the SUVA $\left(\mathrm{UV}_{254} / \mathrm{DOC} \times 100\right)$ value of the permeates decreased as compared with the feed water. It was proposed that there was a larger amount of

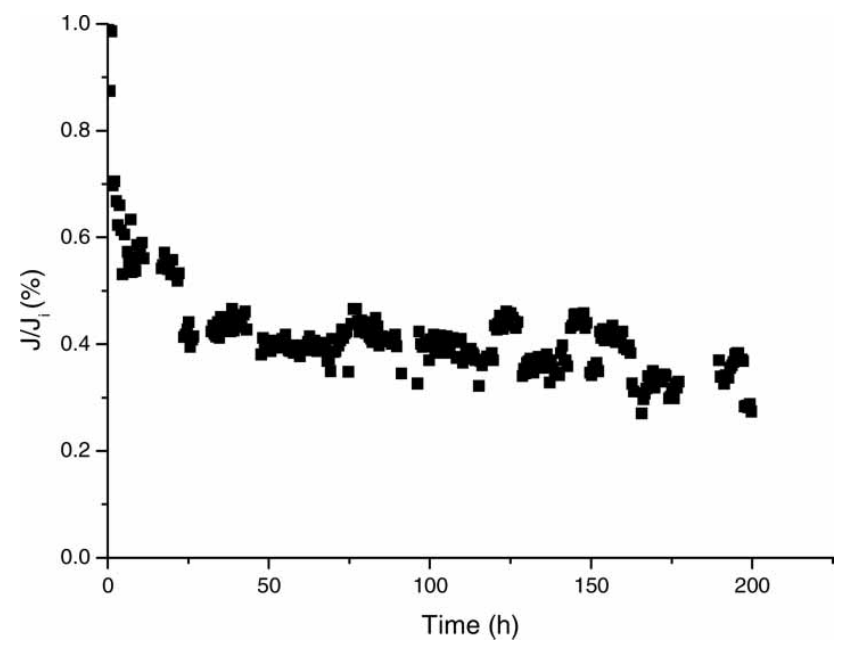

Figure 1 | Flux decline profiles of PS ultrafiltration.
Table 1 | Average amount of organic compounds and related parameters of three water streams: feed, permeate and concentrate

\begin{tabular}{llll} 
Samples & SUVA L/mg $\mathbf{~ m}$ & Doc $\mathbf{~} \mathbf{~} / \mathbf{L}$ & $\mathbf{U V}_{\mathbf{2 5 4}} \mathbf{~ m}^{\mathbf{1}}$ \\
\hline Feed & 3.00 & 0.97 & 0.029 \\
Permeate & 2.80 & 0.82 & 0.023 \\
Concentrate & 2.88 & 1.04 & 0.030 \\
\hline
\end{tabular}

hydrophilic organic compounds in the permeate since the SUVA value represents the aromaticity of dissolved organic matter (Tian et al. 2009).

To investigate the specific fractional composition of each water stream, the resin fractionation analysis was conducted (shown in Figure 2). The permeate was found to have higher hydrophilic DOC (\%) content and relative lower hydrophobic DOC (\%) such as HoA, HoN and HoB fractions. This was consistent with the SUVA value trend.

To further study the organic matter, EEMs of feed, permeate and concentrate were measured and compared (Figure 3). As shown in Figure 3, three apparent peaks are observed. Chen et al. (2003) have reported that peaks at shorter excitation wavelengths $(<250 \mathrm{~nm})$ and shorter emission wavelengths $(<350 \mathrm{~nm})$ were related to simple aromatic proteins such as tyrosine. Peaks at longer excitation wavelengths $(>280 \mathrm{~nm})$ and longer emission wavelengths $(>380 \mathrm{~nm})$ were related to humic acid-like

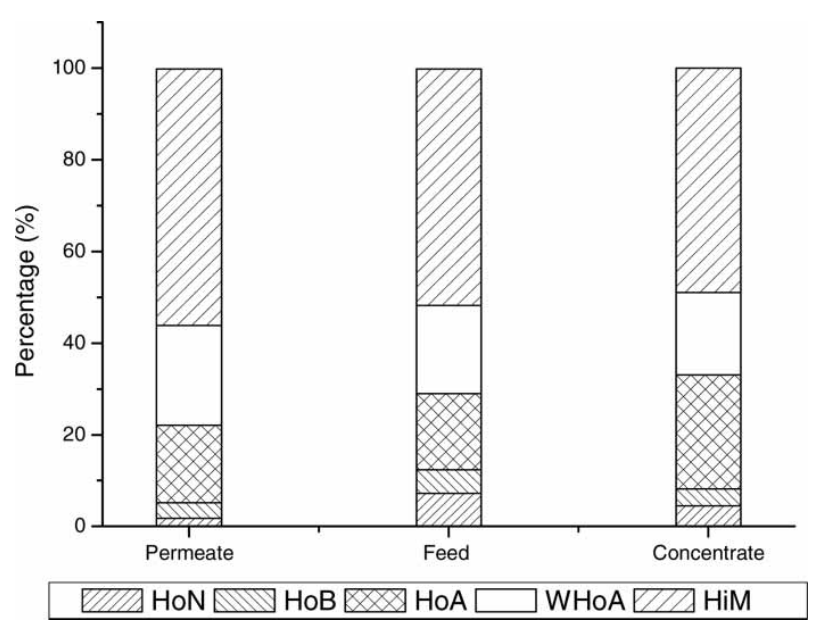

Figure 2 Relative fraction of hydrophobic neutral (HoN), hydrophobic base (HoB), hydrophobic acid (HoA), weekly hydrophobic acid (WHOA) and hydrophilic (HiM) DOM fractions in feed, permeate and concentrate. 

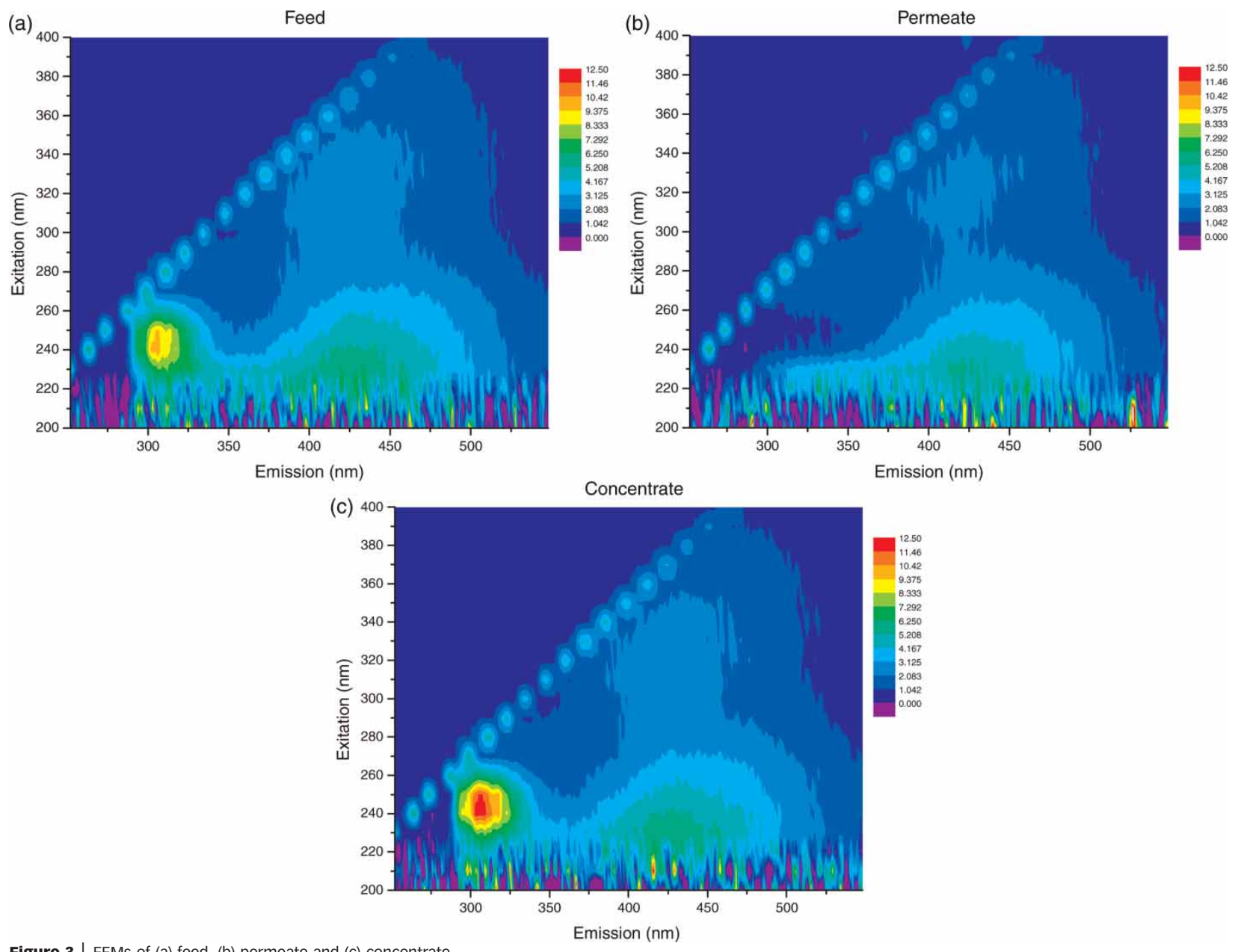

Figure 3 | EEMs of (a) feed, (b) permeate and (c) concentrate.

organics. Peaks at shorter excitation wavelengths $(<250 \mathrm{~nm})$ and longer emission wavelengths $(>350 \mathrm{~nm})$ were related to fulvic acid-like materials. This implied that the feed water contained mainly simple aromatic proteins, humic acid and fulvic acid-like organics. While the aromatic proteins were effectively rejected, and the permeate contained mainly humic and fulvic acid-like organics.

Therefore, it was proposed that hydrophilic fractions of humic acid and fulvic acid of a small size permeated the membrane easier, while the hydrophobic fraction with relatively higher molecular weight or molecular mass were likely to be rejected and retained by the membrane. Their complex molecular structure also prevents components with an aromatic shape from easily passing through the membrane (Zularisam et al. 2007a, b).

\section{ATR-FTIR analysis}

Figure 4 illustrates the ATR-FTIR spectra of the fouled and sponge wiped PS membrane. Filtration of lake waters commonly results in the addition of carboxyl or amide groups to the clean membrane. For the fouled PS membrane, corresponding peaks were detected at wavenumbers 1,540 and $1,650 \mathrm{~cm}^{-1}$ (Ahn et al. 2008). Deprotonated carboxyl groups have two modes of vibration. Peaks arising from asymmetric stretching of $-(\mathrm{C}=\mathrm{O})-\mathrm{O}-$ appear between 1,540 and $1,650 \mathrm{~cm}^{-1}$, while peaks from symmetric stretching appear between 1,200 and $1,300 \mathrm{~cm}^{-1}$ (Cabaniss \& McVey 1995). In addition, stretching of $-\mathrm{C}-\mathrm{O}$ group and $\mathrm{OH}$ deformation of $\mathrm{COOH}$ appear between 1,200 and $1,300 \mathrm{~cm}^{-1}$ in combination with the acid $\mathrm{O}-\mathrm{H}$ stretching bond at $\sim 3,300 \mathrm{~cm}^{-1}$ 


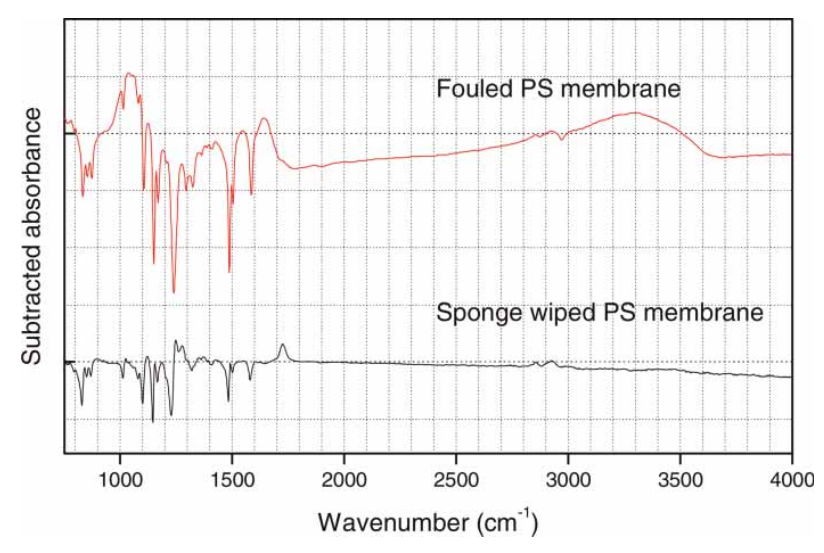

Figure 4 | ATR-FTIR spectra of fouled and sponge wiped PS membranes: ATR-FTIR spectrum of clean PS membrane was digitally subtracted. (a)

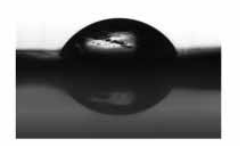

virgin PS membrane $\left(56.5^{\circ}\right)$ (b)

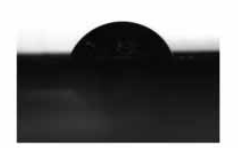

fouled PS membrane $\left(59.7^{\circ}\right)$ (c)

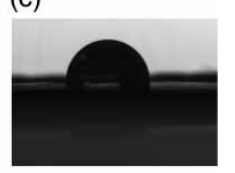

Sponge wiped PS membrane $\left(79.7^{\circ}\right)$
Figure 5 | Contact angles of virgin, fouled and sponge wiped PS membranes.

both of which suggest the presence of humic substances (Zularisam et al. 2006). Due to the similar structure of amide and deprotonated carboxyl groups, vibration frequencies are similar as well. Primary and secondary amide peaks are located at $\sim 1,580$ and $1,650 \mathrm{~cm}^{-1}$, respectively (Cho et al. 1998; Jarusutthirak et al. 2002). Other common peaks were detected at 1,130 and $1,170 \mathrm{~cm}^{-1}$ for the filtration of lakes waters, which was assigned to polysaccharide-like material (Jarusutthirak et al. 2002; Zularisam et al. 2006). The silicon oxide bond (i.e., -Si-O) of clay minerals is apparent at $1,080 \mathrm{~cm}^{-1}$ (Ahn et al. 2008). As described above, the foulant included proteins, humic substances, polysaccharide-like materials and silicon-contained minerals. By contrast, for the sponge wiped PS membrane, the main adsorption bands were $2,940 \mathrm{~cm}^{-1}$ (aliphatic $\mathrm{C}-\mathrm{H}$ stretching), $1,720 \mathrm{~cm}^{-1}(-\mathrm{C}=\mathrm{O}$ stretching band of carboxylic acid), $1,200-1,300 \mathrm{~cm}^{-1}$. The results suggest that the major constituents of the irreversible membrane fouling were humic substances.

\section{Contact angle analysis}

Contact angle analysis was used to investigate the hydrophobicity/hydrophilicity of the membrane surface. The angle of a water drop on the membrane surface was measured by a goniometer. Although it is not a very precise and quantitative methodology, it is still informative in explaining the relative changes of a membrane's properties by fouling (Lee et al. 2004). As shown in Figure 5, the contact angle of the fouled membrane was slightly higher than the virgin membrane. But the contact angle of sponge wiped PS increased to $79.7^{\circ}$. In general, the change in contact angle was primarily influenced by the deposition of organic foulants on the membrane surface, especially the composition of NOM. From this interpretation, these results were in accordance with the findings described above: more (a)

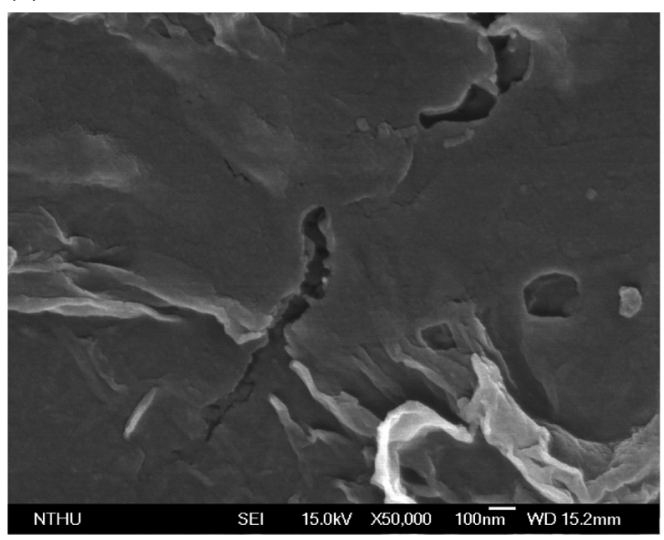

(b)

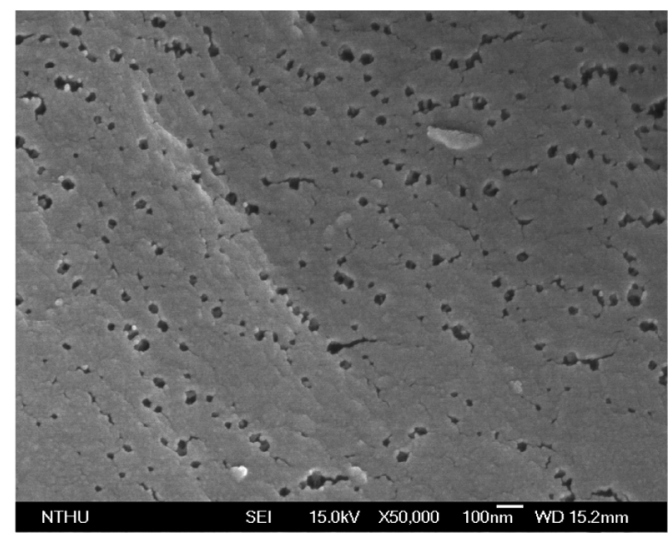

Figure 6 | SEM images of membranes (magnification: ×50,000): (a) fouled PS membrane and (b) sponge wiped PS membrane. 
hydrophobic NOM was rejected by the membrane and the hydrophobic fraction of humic acid could be the potential physically irreversible foulant.

\section{Scanning electron microscopy}

The top surfaces of fouled and sponge wiped PS membranes were observed with an SEM. The images are shown in Figure 6(a) and (b), respectively. Comparing Figures 6(a) and (b), it is can clearly be seen that membrane fouling was very serious after a $200 \mathrm{~h}$ filtration. A compact gel layer covered the surface and caused significant flux reduction while, after manually sponge wiping, most of the membrane surface pores could be clearly observed. This further confirmed that the physically irreversible fouling of the PS membrane was relatively weak with few foulants plugging in the membrane pores.

\section{$\overline{\text { CONCLUSIONS }}$}

In this study, the fouling, and particularly the physically irreversible fouling, of a PS ultrafiltration membrane was investigated. It was found that the hydrophilic fractions of humic acid and fulvic acid of small size were likely to permeate the membrane, whilst it was easier to reject and retain the hydrophobic fraction of humic and fulvic acid and aromatic proteins. Through membrane autopsy, the organic compounds which contained proteins, humic substances and polysaccharide-like materials, were all detected in the fouling layer. But the physically irreversible fouling of the PS membrane seemed to be mainly the hydrophobic fraction of humic substances.

\section{ACKNOWLEDGEMENTS}

This work is supported by the NSF of China under 50908224, 50921064, the national 863 program under 2008AA06A414 and the special fund from the State Key Laboratory of Environmental Aquatic Chemistry (Project 08Y03ESPCR). The authors are grateful to Prof. D.J. Lee (National Taiwan University) for his help in EEM measurement. The kind comments from anonymous reviewers are gratefully acknowledged.

\section{$\overline{\text { REFERENCES }}$}

Ahn, W.-Y., Kalinichev, A. G. \& Clark, M. M. 2008 Effects of background cations on the fouling of polyethersulfone membranes by natural organic matter: experimental and molecular modeling study. Journal of Membrane Science 309 (1-2), 128-140.

Aoustin, E., Schafer, A. I., Fane, A. G. \& Waite, T. D. $200 \mathrm{I}$ Ultrafiltration of natural organic matter. Separation and Purification Technology 22-23, 63-78.

Cabaniss, S. E. \& McVey, I. F. I995 Aqueous infrared carboxylate absorbances: aliphatic monocarboxylates. Spectrochimica Acta Part A: Molecular and Biomolecular Spectroscopy 51 (13), 2385-2395.

Carroll, T., King, S., Gray, S. R., Bolto, B. A. \& Booker, N. A. 2000 The fouling of microfiltration membranes by NOM after coagulation treatment. Water Research 34 (11), 2861-2868.

Chen, W., Westerhoff, P., Leenheer, J. A. \& Booksh, K. 2003 Fluorescence excitation-emission matrix regional integration to quantify spectra for dissolved organic matter. Environmental Science \& Technology 37 (24), 5701-5710.

Cho, J., Amy, G. \& Pellegrino, J. 2000 Membrane filtration of natural organic matter: factors and mechanisms affecting rejection and flux decline with charged ultrafiltration (UF) membrane. Journal of Membrane Science 164 (1-2), 89-110.

Cho, J., Amy, G., Pellegrino, J. \& Yoon, Y. 1998 Characterization of clean and natural organic matter (NOM) fouled NF and UF membranes, and foulants characterization. Desalination 118 (1-3), 101-108.

Fan, L., Harris, J. L., Roddick, F. A. \& Booker, N. A. 200I Influence of the characteristics of natural organic matter on the fouling of microfiltration membranes. Water Research 35 (18), 4455-4463.

Jarusutthirak, C., Amy, G. \& Croue, J.-P. 2002 Fouling characteristics of wastewater effluent organic matter (EfOM) isolates on NF and UF membranes. Desalination 145 (1-3), 247-255.

Kennedy, M. D., Chun, H. K., Quintanilla Yangali, V. A., Heijman, B. G. J. \& Schippers, J. C. 2005 Natural organic matter (NOM) fouling of ultrafiltration membranes: fractionation of NOM in surface water and characterisation by LC-OCD. Desalination 178 (1-3), 73-83.

Lee, N., Amy, G., Croue, J.-P. \& Buisson, H. 2004 Identification and understanding of fouling in low-pressure membrane (MF/UF) filtration by natural organic matter (NOM). Water Research 38 (20), 4511-4523.

Leenheer, J. A. I98I Comprehensive approach to preparative isolation and fractionation of dissolved organic carbon from 
natural waters and wastewaters. Environmental Science \& Technology 15 (5), 578-587.

Li, Q. \& Elimelech, M. 2004 Organic fouling and chemical cleaning of nanofiltration membranes: measurements and mechanisms. Environmental Science \& Technology 38 (17), 4683-4693.

Nilson, J. A. \& DiGiano, F. A. 1996 Influence of NOM composition on nanofiltration. Journal American Water Works Association 88 (5), 53-66.

Tian, J. Y., Chen, Z. L., Yang, Y. L., Liang, H., Nan, J. \& Li, G. B. 2009 Consecutive chemical cleaning of fouled PVC membrane using $\mathrm{NaOH}$ and ethanol during ultrafiltration of river water. Water Research 44 (1), 59-68.

Wei, Q. S., Feng, C. H., Wang, D. S., Shi, B. Y., Zhang, L. T., Wei, Q. \& Tang, H. X. 2008 Seasonal variations of chemical and physical characteristics of dissolved organic matter and trihalomethane precursors in a reservoir: a case study. Journal of Hazardous Materials $\mathbf{1 5 0}$ (2), 257-264.
Yamamura, H., Kimura, K. \& Watanabe, Y. 2007 Mechanism involved in the evolution of physically irreversible fouling in microfiltration and ultrafiltration membranes used for drinking water treatment. Environmental Science \& Technology 41 (19), 6789-6794.

Yuan, W. \& Zydney, A. L. 1999 Humic acid fouling during microfiltration. Journal of Membrane Science 157 (1), 1-12.

Zularisam, A. W., Ismail, A. F., Salim, M. R., Sakinah, M. \& Hiroaki, O. 2007a Fabrication, fouling and foulant analyses of asymmetric polysulfone (PSF) ultrafiltration membrane fouled with natural organic matter (NOM) source waters. Journal of Membrane Science 299 (1-2), 97-113.

Zularisam, A. W., Ismail, A. F., Salim, M. R., Sakinah, M. \& Ozaki, H. 2007b The effects of natural organic matter (NOM) fractions on fouling characteristics and flux recovery of ultrafiltration membranes. Desalination 212 (1-3), 191-208.

Zularisam, A. W., Ismail, A. F. \& Salim, R. 2006 Behaviours of natural organic matter in membrane filtration for surface water treatment - a review. Desalination 194 (1-3), 211-231.

First received 1 June 2010; accepted in revised form 25 August 2010 